\title{
Hsp70 - a biomarker for tumor detection and monitoring of outcome of radiation therapy in patients with squamous cell carcinoma of the head and neck
}

Mathias Gehrmann ${ }^{1}$, Hanno M Specht ${ }^{1}$, Christine Bayer ${ }^{1}$, Markus Brandstetter ${ }^{2}$, Barbara Chizzali', Marciana Duma', Stephanie Breuninger ${ }^{1}$, Kathrin Hube ${ }^{1}$, Sophie Lehnerer ${ }^{1}$, Valerie van Phi ${ }^{1}$, Eva Sage ${ }^{1}$, Thomas E Schmid ${ }^{1}$, Michael Sedelmayr ${ }^{1}$, Daniela Schilling ${ }^{1,3}$, Wolfgang Sievert ${ }^{1}$, Stefan Stangl ${ }^{1}$ and Gabriele Multhoff ${ }^{1,3^{*}}$

\begin{abstract}
Background: Tumor but not normal cells frequently overexpress heat shock protein 70 (Hsp70) and present it on their cell surface ( $\mathrm{mHsp70}$ ) from where it can be actively released. Therefore, membrane ( $\mathrm{mHsp70)}$ and soluble Hsp70 (sHsp70) were investigated as potential tumor biomarkers and for monitoring the outcome of radiation therapy.

Methods: Biopsies and blood were collected from patients with squamous cell carcinoma of the head and neck $(\mathrm{SCCHN}$ ) at different time points (before, during therapy and in the follow-up period). Hsp70 membrane expression was determined on single cell suspensions of tumor biopsies and reference tissues by flow cytometry, sHsp70 protein and antibody levels were determined in the serum of patients and healthy donors by ELISA and NK cell markers that are related to the presence of sHsp70 were analyzed in the patient's peripheral blood lymphocytes (PBL).

Results: Tumor biopsies exhibited significantly increased $\mathrm{mHsp} 70$ expression levels compared to the reference tissue. Soluble Hsp70 levels were significantly higher in SCCHN patients compared to healthy human volunteers and high mHsp70 expression levels on tumor cells were associated with high sHsp70 levels in the serum of patients. Following surgery and radiotherapy sHsp70 levels in patients dropped in patients without tumor relapse in the follow-up period. In contrast to sHsp70 protein, anti-Hsp70 antibody levels remained nearly unaltered in the serum of SCCHN patients before and after therapy. Furthermore, sHsp70 protein but not anti-Hsp70 antibody levels were found to be associated with the tumor volume in SCCHN patients before start of therapy. The expression densities of the activatory NK cell markers CD56, CD94, NKG2D, NKp30, Nkp44, and NKp46 differed in patients following therapeutic intervention. A significant increase in the density of NKG2D was observed in SCCHN patients in the follow-up period after surgery and radiotherapy.
\end{abstract}

Conclusion: We suggest sHsp70 as a potential biomarker for detecting tumors and for monitoring the clinical outcome of radiotherapy in SCCHN patients.

Keywords: Hsp70, Tumor, Biomarker, Radiation therapy

\footnotetext{
*Correspondence: gabriele.multhoff@|rz.tum.de

'Department of Radiation Oncology, Klinikum rechts der Isar, Technische

Universität München, Munich, Germany

${ }^{3}$ Clinical Cooperation Group - "Innate Immunity in Tumor Biology",

Helmholtz Zentrum münchen, Munich, Germany

Full list of author information is available at the end of the article
} 


\section{Introduction}

Biomarkers are getting more and more important for a better prognosis and for and improved follow-up of a therapy as recently shown for gastro-intestinal tumors $[1,2]$. Optimal biomarkers should be presented on the cell surface of a broad variety of tumor cells but not on normal cells and should be released in a tumor-specific manner. In order to use biomarkers for the prediction of outcome it is important that the biomarkers remain stable during therapeutic intervention. The presence of biomarkers in the urine or blood of a patient allows repeated tests with a minimal invasive intervention.

For a long time heat shock proteins including Hsp70 and auto-antibodies directed against them have been shown to provide useful biomarkers for the prediction of prostate cancer [3] and squamous cell carcinoma of the oesophagus [4]. Elevated heat shock protein levels have been detected in many different types of cancer [5]. Nevertheless, the approaches have not been validated sufficiently and thus are yet not in clinical use. Hsp70 the major stress-inducible member of the HSP70 family has the potential for being a predictive marker molecule for several reasons. Hsp70 is overexpressed in many different tumor types; it is protecting cells from DNA damage [6], and exerts anti-apoptotic functions [7]. Overexpressed inside cells, Hsp70 is transported to the cell membrane and also exported into the extracellular space [8]. The transport routes are not following the classical transport routes through the ER and Golgi apparatus but instead are mediated through endosomal and lysosomal vesicles [9]. Only a small proportion of Hsp70 is released as free Hsp70 by necrotic cell death. Our findings demonstrate that the majority of extracellular Hsp70 is bound to small lipid vesicles [9]. Theses vesicles are actively released by tumor cells presumably for signaling purposes. It already has been shown that released Hsp70 can stimulate the adaptive immune system [10]. NK cells also recognize Hsp70, bind it and thus can be activated [11]. Following activation, NK cells actively migrate towards Hsp70 positive tumor cells, and kill them via the release of the cytotoxic enzyme granzyme B [12].

Extracellular Hsp70 can be detected by ELISA. Recent results of our group show that Hsp70 can be detected in the plasma of mice bearing human xenograft tumors [13]. Additionally, the plasma Hsp70 levels correlate with the tumor burden of mice assuming the potential of Hsp70 as predictive tumor marker.

Since Hsp70 can be released by human tumor cells with a membrane Hsp70-positive phenotype, we studied the diagnostic impact of sHsp70 in serum of patients suffering from SCCHN. Serum levels of sHsp70 were assessed in patients before and at different time points after radiation therapy and compared to that of healthy controls. In order to study the role of $\mathrm{sHsp70}$ as a potential stimulator of NK cells we concomitantly studied the expression of activatory NK cell markers on the PBL of the patients.

\section{Patients and methods \\ Patients}

In total, 21 (20 male, 1 female) patients suffering from tumors localized in the oral cavity (5 cases), larynx (6), oro/hypopharynx (2), oropharynx (7), sinus (1) and 28 age-matched healthy human volunteers were enrolled into the study (Tables 1 and 2). The mean age of all patients was 66.7 years (range 38-78) with a median of 66.0 years and that of healthy individuals was 61.0 (mean 47-74) with a mean of 61.5 years, respectively (Table 1 ). The clinicopathological characteristics and the treatment regime of each individual patient are summarized in Table 2. Tumor volume was determined by manually contouring the gross tumor volume (GTV) based on contrast enhanced computer tomography scans using iPlan planning software (Brainlab, Feldkirchen, Germany). Total radiation doses following tumor excision were 64 Gy (11 patients), and 60 Gy (2 patients), respectively. One patient received a definitive radiation with a total dose of $70 \mathrm{~Gy}$, and 7 patients received no adjuvant radiation therapy following complete tumor resection. All patients and healthy human individuals provided written informed consent for the collection of blood and tumor biopsies which was approved by the Ethics Committee of the Klinikum rechts der Isar der Technischen Universität München. Blood was collected from untreated tumor patients before surgery and adjuvant radiotherapy and at indicated time points after tumor excision and radiotherapy by venepuncture. $9 \mathrm{ml}$ EDTA-blood and $9 \mathrm{ml}$ serum were collected in S-Monovettes (Sarstedt, Nümbrecht, Germany).

\section{Tumor biopsies}

Biopsies in the size range of a few $\mathrm{mm}^{3}$ were taken during tumor excision. As a reference, connective tissues derived from 7 tumor-free donors were collected. Single cell suspensions from freshly isolated tumor biopsies were isolated by mechanical disintegration and by forcing the cell suspension through a sterile mesh $(75 \mu \mathrm{m})$

Table 1 Age and gender of SCCHN patients and healthy human volunteers

\begin{tabular}{|c|c|c|c|}
\hline & Healthy controls & SCCHN patients \\
\hline \multicolumn{2}{|c|}{ Number (n) } & 28 & 21 \\
\hline \multicolumn{2}{|c|}{ Gender (M/F) } & $12 / 16$ & $20 / 1$ \\
\hline \multirow[t]{3}{*}{ Age } & Mean (Range) & $61.0(47-74)$ & $66.7(38-78)$ \\
\hline & SD & 7.0 & 9.2 \\
\hline & Median & 61.5 & 66.0 \\
\hline
\end{tabular}

Abbreviations: $M$ male, $F$ female, $S D$ standard deviation, SCCHN Squamous Cell Carcinoma of the Head and Neck. 
Table 2 Clinicopathological characteristics of all SCCHN patients

\begin{tabular}{|c|c|c|c|c|c|c|c|}
\hline \multirow[t]{2}{*}{ Patient \# } & \multirow[t]{2}{*}{ Tumor location } & \multicolumn{3}{|c|}{ Stadium } & \multirow[t]{2}{*}{ Grading } & \multicolumn{2}{|c|}{ Therapy } \\
\hline & & $T$ & $\mathrm{~N}$ & $\bar{M}$ & & Surgery & RTx dose (Gy) \\
\hline 1 & Oral cavity & 2 & $2 \mathrm{~cd}$ & 0 & 2 & + & 0 \\
\hline 2 & Larynx & 4 & $2 b$ & 0 & 3 & + & 64 \\
\hline 3 & Oral Cavity & 1 & 0 & 0 & 2 & + & 60 \\
\hline 4 & Oro/Hypopharynx & 4 & $2 a$ & 0 & 2 & + & 64 \\
\hline 5 & Oropharynx & 3 & 2 & 0 & 2 & - & 70 \\
\hline 6 & Oropharynx & 1 & $2 b$ & 0 & 3 & + & 64 \\
\hline 7 & Oral Cavity & 1 & $2 \mathrm{a}$ & 0 & 2 & + & 64 \\
\hline 8 & Oro/Hypopharynx & 1 & 0 & 0 & 2 & + & 64 \\
\hline 9 & Oral Cavity & 1 & 0 & 0 & 2 & + & 64 \\
\hline 10 & Oral Cavity & 1 & 0 & 0 & 3 & + & 0 \\
\hline 11 & Oropharynx & 2 & $2 a$ & 0 & 2 & + & 0 \\
\hline 12 & Larynx & 2 & $2 b$ & 0 & 3 & + & 0 \\
\hline 13 & Oropharynx & 4 & 0 & 0 & 2 & + & 64 \\
\hline 14 & Oropharynx & 2 & 0 & 0 & 3 & + & 64 \\
\hline 15 & Larynx & 3 & 0 & 0 & 3 & + & 64 \\
\hline 16 & Larynx & 4 & 1 & 0 & 3 & + & 0 \\
\hline 17 & Oropharynx & 2 & $2 b$ & 0 & 3 & + & 0 \\
\hline 18 & Oropharynx & 2 & 1 & 0 & 2 & + & 64 \\
\hline 19 & Larynx & 2 & 1 & 0 & 2 & + & 64 \\
\hline 20 & Sinus & 2 & 0 & 0 & 3 & + & 60 \\
\hline 21 & Larynx & 4 & 0 & 0 & 3 & + & 0 \\
\hline
\end{tabular}

to obtain single cell suspensions according to a method described previously [14].

\section{Serum}

Blood was centrifuged at $750 \times \mathrm{g}$ at room temperature (RT) for $10 \mathrm{~min}$ the supernatant containing the serum was removed, mixed, and stored at $-80^{\circ} \mathrm{C}$ in aliquots. Sera were used for experiments after thawing only once. Control serum samples were collected from age-matched healthy human volunteers (Table 1).

\section{ELISA assays}

Total sHsp70 levels in serum samples of humans were measured using a modified Hsp70 immunoassay (Duoset, DYC1663, R\&D Systems, Minneapolis, MN, USA). The ELISA is designed to detect human Hsp70 in buffer. All serum samples were analyzed in three independent experiments in duplicates.

Anti-Hsp70 antibodies in the serum were detected using a sandwich ELISA. Briefly, Hsp70 protein (ADINSP-555, Enzo Life Sciences, Farmingdale, NY, USA) was coated onto MaxiSorp 96-well plates (NuncNalgene, Thermo Fisher Scientific, Waltham, MA, USA). After incubation with serum the bound antibodies were detected by incubation with HRP-conjugated anti-human
Ig followed by HRP-substrate (DY999, R\&D Systems, Minneapolis, MN, USA).

\section{Flow cytometry}

Single cells from freshly isolated tumor biopsies were prepared by mechanical disintegration of the tissue, as described previously [14]. $1 \times 10^{5}$ cells were washed once with 10\% FCS in PBS and incubated with a FITCconjugated mouse monoclonal antibody specific for membrane-bound Hsp70 (cmHsp70.1, IgG1, multimmune $\mathrm{GmbH}$, Munich, Germany) or a FITC-labeled isotypematched IgG1 negative control antibody (345815, BD Biosciences, Franklin Lakes, NJ, USA) on ice in the dark for $30 \mathrm{~min}$. After washing, propidium iodide was added and viable cells were analyzed on a FACSCalibur flow cytometer (BD Biosciences). The percentage of cells stained with an isotype-matched control antibody was subtracted from the percentage of mHsp70 positive cells.

NK cell markers were determined in the peripheral blood of the patients by flow cytometry as described previously [15]. After incubation with fluorescence-conjugated antibodies (CD56, CD94, CD3, CD94, NKG2D, NKp30, NKp44, NKp46), or the appropriate mouse isotypematched control antibodies, erythrocytes were lysed using 
the FACS lysing Solution (BD Biosciences) according the manufacturer's instructions. After washing, lymphocytes were analyzed on a FACSCalibur flow cytometer (BD Biosciences). The NK cells were gated according to their CD56 positivity and CD3 negativity. The percentage of cells stained with an isotype-matched control antibody was subtracted from the percentage of antibody-positively stained cells.

\section{Statistical analysis}

Statistical analysis was performed using SigmaPlot software delivered by Systat Software Inc. (San Jose, CA, USA). Results for the levels of mHsp70, sHsp70, or antiHsp70 antibodies are presented as standard box plots with boundaries indicating the $25^{\text {th }}$ and the $75^{\text {th }}$ percentile. The line inside boxes indicates the median and the whiskers indicate the $10^{\text {th }}$ and $90^{\text {th }}$ percentile, respectively. All outliers are shown. The square of the coefficient of correlation parameter $\mathrm{R}^{2}$ and linear regression analysis were used to determine the relationships between variables. For comparison between groups of data the student's $t$-test was used to evaluate differences. $p$ values $<0.05$ were considered to be statistically significant.

\section{Results}

\section{Hsp70 membrane expression on tumor biopsies of} SCCHN patients

Tumor biopsies were obtained from patients with SCCHN by tumor resection $(n=21)$ and reference connective tissues of tumor-free donors $(n=7)$. The Hsp70 membrane status (mHsp70) was determined on viable single cell suspensions by flow cytometric (FACS) analysis using
cmHsp70.1 monoclonal antibody. The mean percentage of Hsp70 positive cells was significantly higher in tumor patients compared to that of the tissue of 7 control tissues which were prepared in parallel (mean 38\% vs. 13\%) (Figure 1A). The percentage of mHsp70 positive cells in patient biopsies ranged between 5 to $100 \%$. According to their Hsp70 membrane status, the results of the patient samples could be divided into two subgroups. The mean percentage of mHsp70 positive cells in the group with a high Hsp70 expression $(n=11)$ was around $83 \%$ and that of the low Hsp70 expressing group $(n=1)$ was $20 \%$ (Figure 1A, boxplots on the right hand side). The mean fluorescence intensity values correlated with the data of the percentage of Hsp70 membrane positive cells (Figure 1B).

\section{sHsp70 serum levels in patients with SCCHN}

To address the question whether the membrane Hsp70 expression correlates with the soluble Hsp70 (sHsp70) serum levels, sHsp70 levels were determined in serum of SCCHN patients before start of any therapy. The mean sHsp70 levels were significantly elevated in SCCHN patients $(5.3 \pm 4.1 \mathrm{ng} / \mathrm{ml}, \mathrm{n}=21)$ compared to agematched healthy human volunteers $(2.2 \pm 0.6 \mathrm{ng} / \mathrm{ml}$, $\mathrm{n}=28$ ) (Figure 2A). Patients with tumors that exhibit a high Hsp70 membrane (mHsp70) expression (Figure 1, high) also exhibited higher sHsp70 serum levels (7.2 \pm $6.7 \mathrm{ng} / \mathrm{ml}, \mathrm{n}=11$ ) than patients with a low (Figure 1, low) Hsp70 membrane expression $(3.4 \pm 1.2 \mathrm{ng} / \mathrm{ml}, \mathrm{n}=10)$ (Figure 2B).

Receiver operating characteristic (ROC) curve analysis was performed to explore the potential role of sHsp70 in
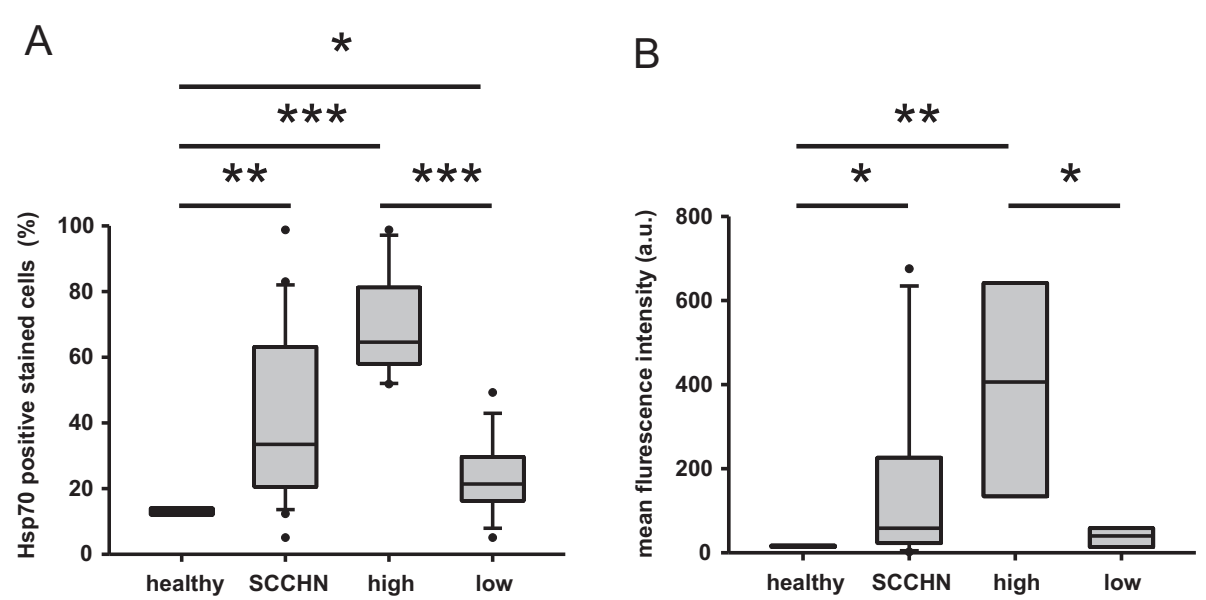

Figure 1 Hsp70 membrane expression on biopsies of SCCHN patients. A. The cells stained with FITC-labeled cmHsp70.1 monoclonal antibody corrected with lgG1 isotype-matched control antibody are depicted in box plots. Data from patients' tumor cells ( $\mathrm{n}=21$ ) were divided into low $(n=10)$ and high $(n=11)$ mHsp70 expressing cells. Single cells from healthy donors $(n=7)$ derived from connective tissues were used as controls. B. Mean fluorescence intensity from the same data set as shown in A. Standard box plots are shown with boundaries indicating the $25^{\text {th }}$ and the $75^{\text {th }}$ percentile. The line inside boxes indicates the median and the whiskers indicate the $10^{\text {th }}$ and $90^{\text {th }}$ percentile, respectively. All outliers are included into the graphs. $\left.{ }^{*} p<0.05,{ }^{* *} p<0.01,{ }^{* * *} p<0.001\right)$. 

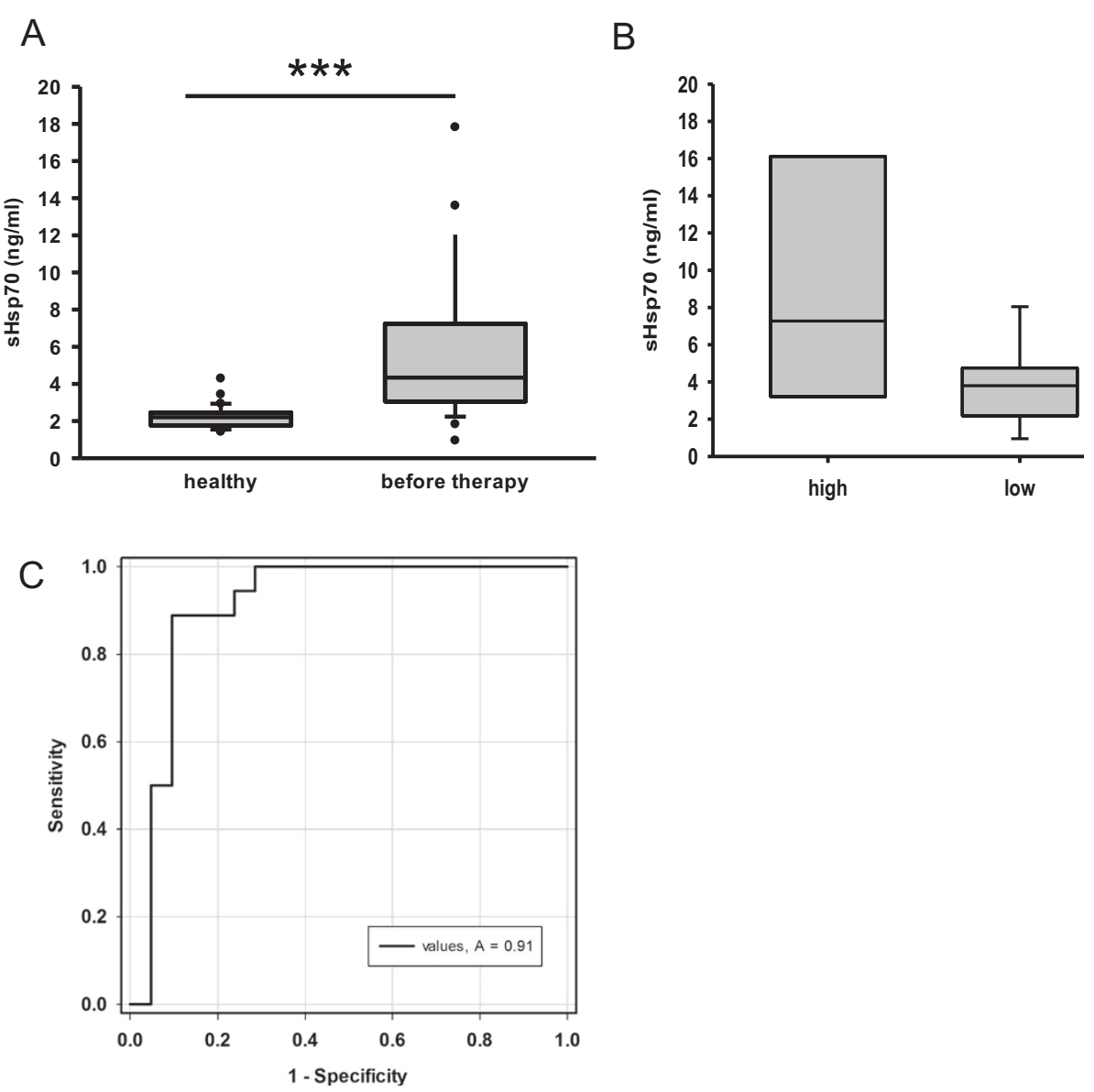

Figure 2 sHsp70 serum levels in blood of patients with SCCHN. A. sHsp70 concentrations in sera of patients $(n=21)$ before therapy compared to healthy donors $(n=28)$. B. sHsp70 serum data from patients were separated into two groups (high $n=11$, low $n=10$ ) reflecting the mHsp70 membrane expression as measured in A. C. Standard box plots are shown with boundaries indicating the $25^{\text {th }}$ and the $75^{\text {th }}$ percentile. The line inside boxes indicates the median and the whiskers indicate the $10^{\text {th }}$ and $90^{\text {th }}$ percentile, respectively. All outliers are shown. $\left(^{* * *} p<0.001\right)$ C. ROC curve of data from (A) were attained by SigmaPlot software showing an AUC of 0.9101 ( $p<0.0001, \mathrm{Cl} 95 \%$ ). The cut-off level was $2.5 \mathrm{ng} / \mathrm{ml}$ with a sensitivity of $89 \%$ and a specificity of $91 \%)$. Abbr:. ROC, receiver operating characteristic; AUC, area under the curve; $\mathrm{Cl}$, confidence interval.

serum as a diagnostic tumor biomarker for SCCHN. The sHsp70 levels of healthy donors were compared to that of SCCHN patients. The ROC curve reveals an area under the curve (AUC) of 0.91 ( $\mathrm{p}<0.0001, \mathrm{CI} 95 \%)$. This means that the cut-off level was $2.5 \mathrm{ng} / \mathrm{ml}$ with a sensitivity of $89 \%$ and with a specificity of $91 \%$ for sHsp70 as a tumor biomarker.

\section{Time-dependent alterations in sHsp70 and anti-Hsp70 antibody levels in the serum of SCCHN patients}

An ideal tumor biomarker should be able to predict clinical responses to therapy, such as radiation therapy or surgery. Soluble Hsp70 levels were found to be significantly elevated in tumor patients before therapy $(5.3 \pm$ $4.1 \mathrm{ng} / \mathrm{ml}, \mathrm{n}=21)$ compared to healthy donors $(2.2 \pm$ $0.6 \mathrm{ng} / \mathrm{ml}, \mathrm{n}=28)$. The levels remained elevated up to 6 weeks after tumor resection $(7.0 \pm 3.6 \mathrm{ng} / \mathrm{ml}, \mathrm{n}=10)$ (Figure 3, during therapy). In the first and second follow- up year after radiotherapy sHsp70 levels dropped to $3.4 \pm$ $1.4 \mathrm{ng} / \mathrm{ml}(\mathrm{n}=9)$ and $3.1 \pm 1.1 \mathrm{ng} / \mathrm{ml}(\mathrm{n}=14)$, respectively (Figure 3, follow-up 1st year, follow-up 2nd year).

The mean anti-Hsp70 antibody concentrations were not significantly different in tumor patients before therapy $(122 \pm 119 \mathrm{ng} / \mathrm{ml}, \mathrm{n}=16)$ and in healthy human volunteers $(84 \pm 64 \mathrm{ng} / \mathrm{ml})$, as shown in Figure 4. Also after therapy (surgery/radiotherapy) the mean anti-Hsp70 antibody concentrations in the serum did not change significantly $(140 \pm 119 \mathrm{ng} / \mathrm{ml}, \mathrm{n}=6)$.

\section{Correlation of sHsp70 protein and anti-Hsp70 antibody} levels with the tumor volume of the patients with SCCHN To evaluate whether the serum levels of sHsp70 protein or anti-Hsp70 antibodies correlate with tumor volumes, the tumor volumes were determined by using CT images. The tumor size in the cohort of SCCHN patients $(n=13)$ before radiation therapy ranged from below $10 \mathrm{ml}$ up 


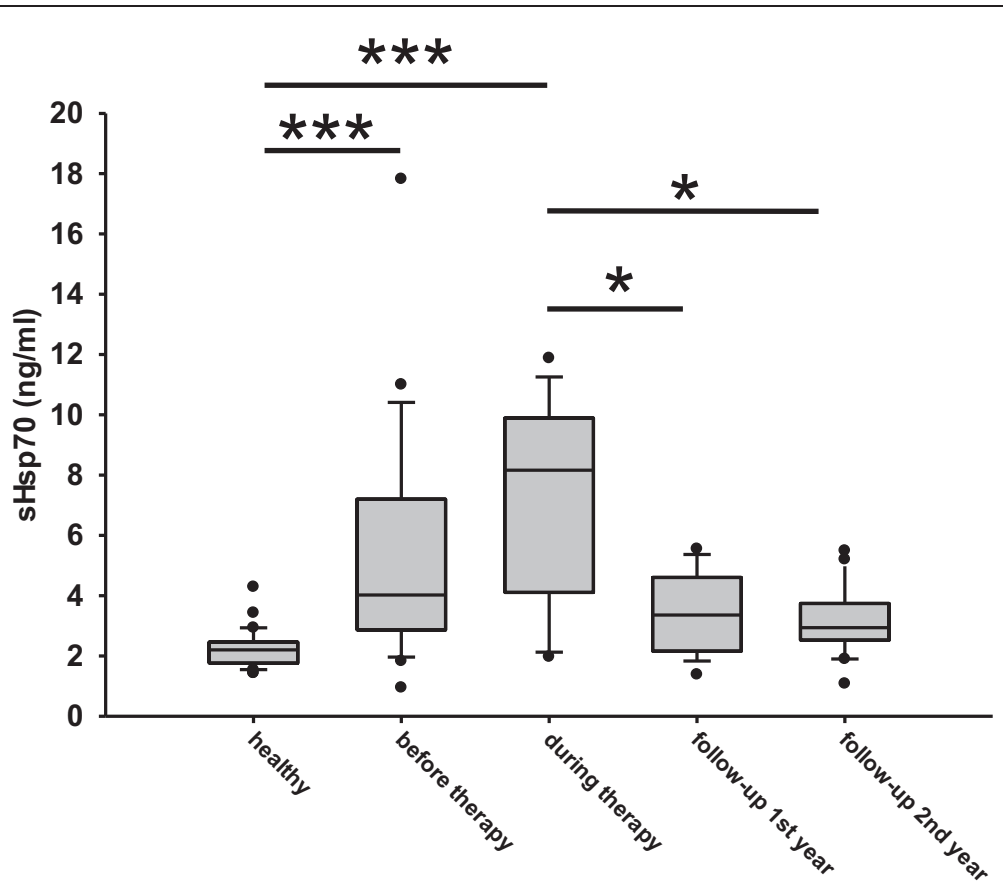

Figure $3 \mathrm{sHsp70}$ levels in the serum of SCCHN patients untreated and after therapy. Blood was collected from patients with SCCHN. sHsp70 concentration was measured with ELISA in three independent experiments in duplicates. Standard box plots are shown with boundaries indicating the $25^{\text {th }}$ and the $75^{\text {th }}$ percentile. The line inside boxes indicates the median and the whiskers indicate the $10^{\text {th }}$ and $90^{\text {th }}$ percentile, respectively. All outliers are shown in the graph. (healthy $n=28$, before therapy $n=21$, during therapy $n=10$, follow-up $1^{\text {st }}$ year $n=9$, follow-up $2^{\text {nd }}$ year $n=14)$. The reason for the different $n$ numbers is due to some missing blood samples during the course of disease. $\left({ }^{*} p<0.05,{ }^{* * *} p<0.001\right)$.

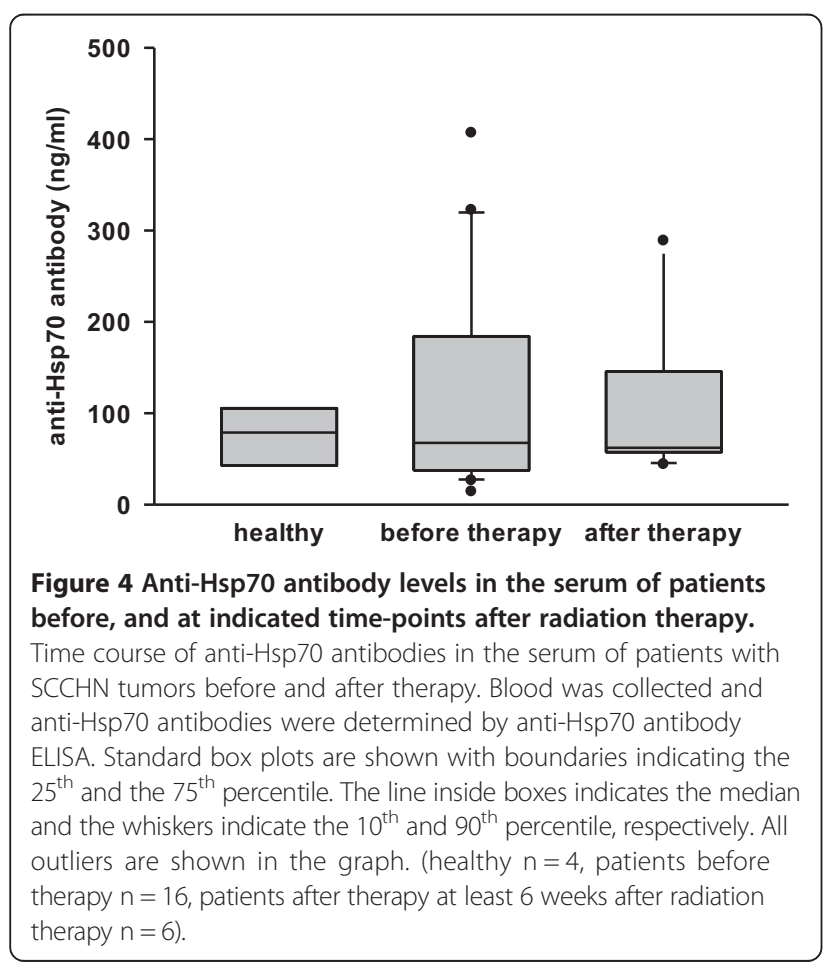

to $>40 \mathrm{ml}$ (the maximum tumor size was $65 \mathrm{ml}$ ). Although not statistically significant, the detected serum sHsp70 levels in patients with larger tumor volumes were higher than in patients with smaller tumors $\left(R^{2}=0.6427\right)$ (Figure 5A), whereas the anti-Hsp70 antibody levels in the serum showed no association with the tumor volume $\left(R^{2}=0.1198\right)$ (Figure 5B).

\section{Expression of activatory NK cell receptors on PBL of SCCHN patients}

In order to test the relevance of the sHsp70 with respect to the stimulation of an NK cell mediated immune response, the expression of activatory NK cell markers was assessed in the blood samples of selected patients before tumor excision and at indicated later time points after radiotherapy. The expression density of the markers CD56, CD94, NKp30, NKp44, and NKp46 varied in the tested patients before, during therapy and within the follow-up period (Figure 6A-F). With respect to the receptor NKG2D, the expression density gradually increased throughout the whole monitoring period in all patients (Figure 6C). A significant increase in the expression density of NKG2D was observed in the blood of patients before therapy (1) and after the second follow-up year (4) (Figure 6G, $\mathrm{n}=7$ ). 


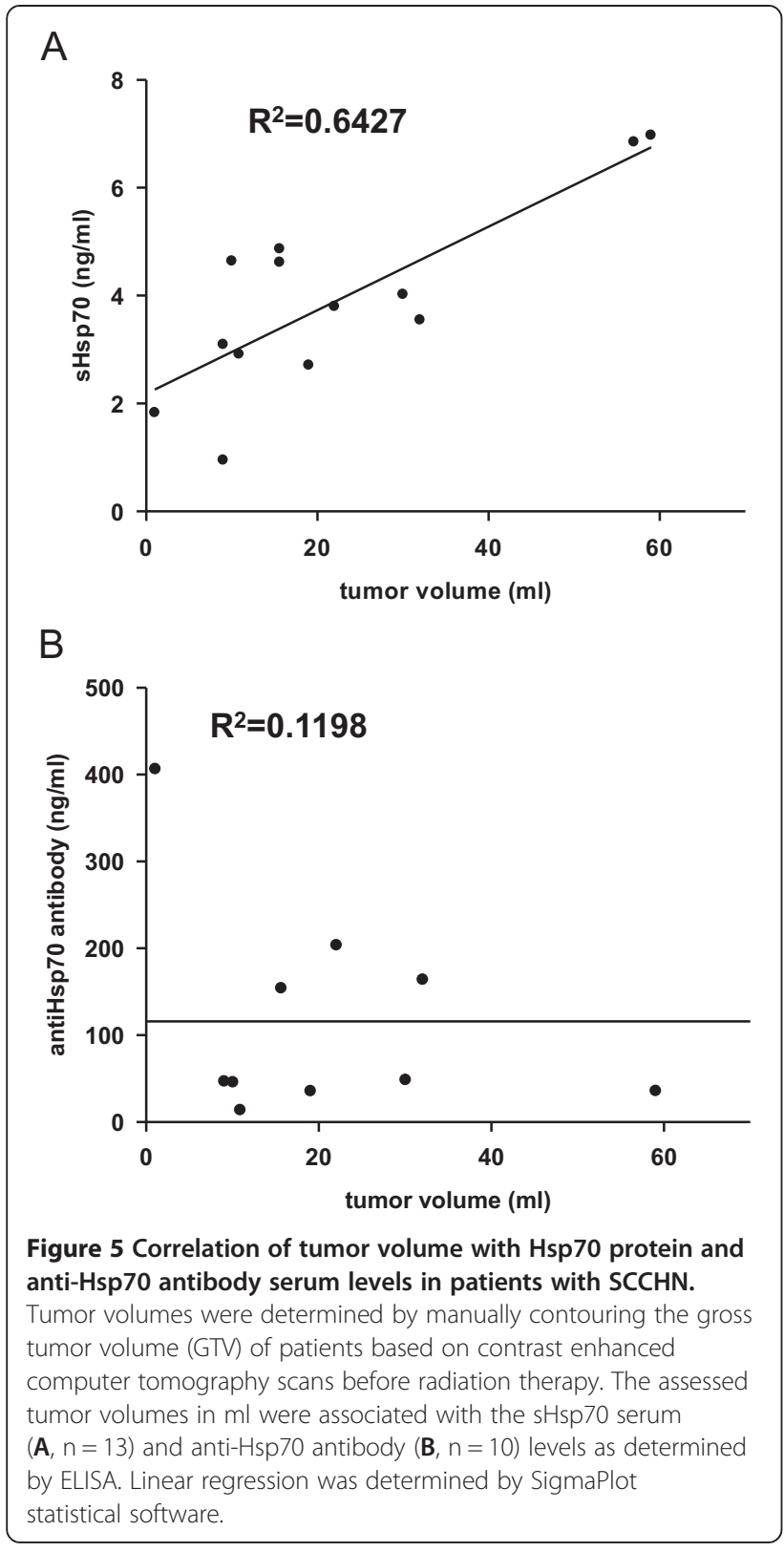

\section{Discussion}

Tumor biomarkers are useful tools for tumor detection and for monitoring the clinical outcome. Instead of tumor biopsies, which are difficult to obtain, blood samples that can be taken regularly by minimal invasive methods qualify much better to measure clinical outcome. Heat shock proteins are frequently overexpressed in tumor cells and thus are reported as biomarkers [5], in prostate [3], and in pancreatic carcinomas [16]. It also has been shown previously that elevated Hsp70 levels can act as a read-out for the efficacy of Hsp90 inhibitorbased therapies [17]. Also autoantibodies directed against Hsp70 in squamous cell carcinoma [4] are discussed as potential biomarkers.
As already demonstrated for other tumor entities [14] also SCCHN tumors are frequently found to be Hsp70 membrane-positive (Figure 1). Furthermore, in our relatively small cohort of 21 patients two subgroups could be identified that differ in their Hsp70 membrane positivity. Eleven patients showed a high and ten patients a low Hsp70 membrane expression. A longer follow-up of the patients and the testing of a larger cohort of patients will elucidate whether differences in the membrane Hsp70 density has an impact on diagnosis or clinical outcome. Furthermore, we could show that the Hsp70 membrane expression on the tumor biopsy was associated with increased sHsp70 serum levels (Figure 2). Elevated sHsp70 levels were detectable up to six weeks after tumor resection (Figure 3). A slight increase in sHsp70 serum levels might be explained by $\mathrm{sHsp70}$ which is released by dying cells during therapy. Within the first and second year follow-up period the sHsp70 levels dropped significantly in patients who did not relapse. In contrast to the sHsp70 protein the levels of anti-Hsp70 antibodies were only slightly increased in tumor patients compared to that of healthy individuals.

We could show that in a well-established $\mathrm{FaDu}$ xenograft tumor mouse model of human SCCHN, sHsp70 concentrations correlated with the tumor volume even in very small tumor sizes of $\approx 1 \mathrm{~mm}^{3}$ [13]. Therefore, we speculate that sHsp70 levels might be useful in screening tests that aim to detect cancer at early stages or in small tumors or metastases also in humans. The $\mathrm{FaDu}$ xenograft model is frequently used to investigate the outcome of radiation therapy [18]. We could show that sHsp70 plasma levels were able to monitor local control of $\mathrm{FaDu}$ tumors in mice after irradiation with 30 Gy [13]. Therefore, a drop in serum sHsp70 levels might be able to predict the clinical outcome of radiotherapy in humans.

It has been shown that Hsp70 is actively released by viable, intact tumor cells and also at a lower level by dying cells [13]. Thus the detectable sHsp70 in the serum or plasma might be composed of two different sources. Other laboratories reported on increased levels of circulating sHsp70 up to several days after whole-body irradiation of mice bearing xenograft prostate tumors [19] that might be explained by dying cells. The slight increase in sHsp70 levels after radiation therapy might account for sHsp70 which is released by dying cells. Apart from dying cells viable tumor cells actively secrete large amounts of Hsp70 in vesicles. In order to evaluate the amount sHsp70, serum samples were derived of patients with SCCHN before start of any therapy. 18 out of 21 tumor patients showed significantly elevated sHsp70 levels in sera compared to healthy control subjects (Figure 1). We further could show that sHsp70 protein but not anti-Hsp70 antibody levels could be associated with the tumor volume in SCCHN patients (Figure 5A). Further analysis and larger 


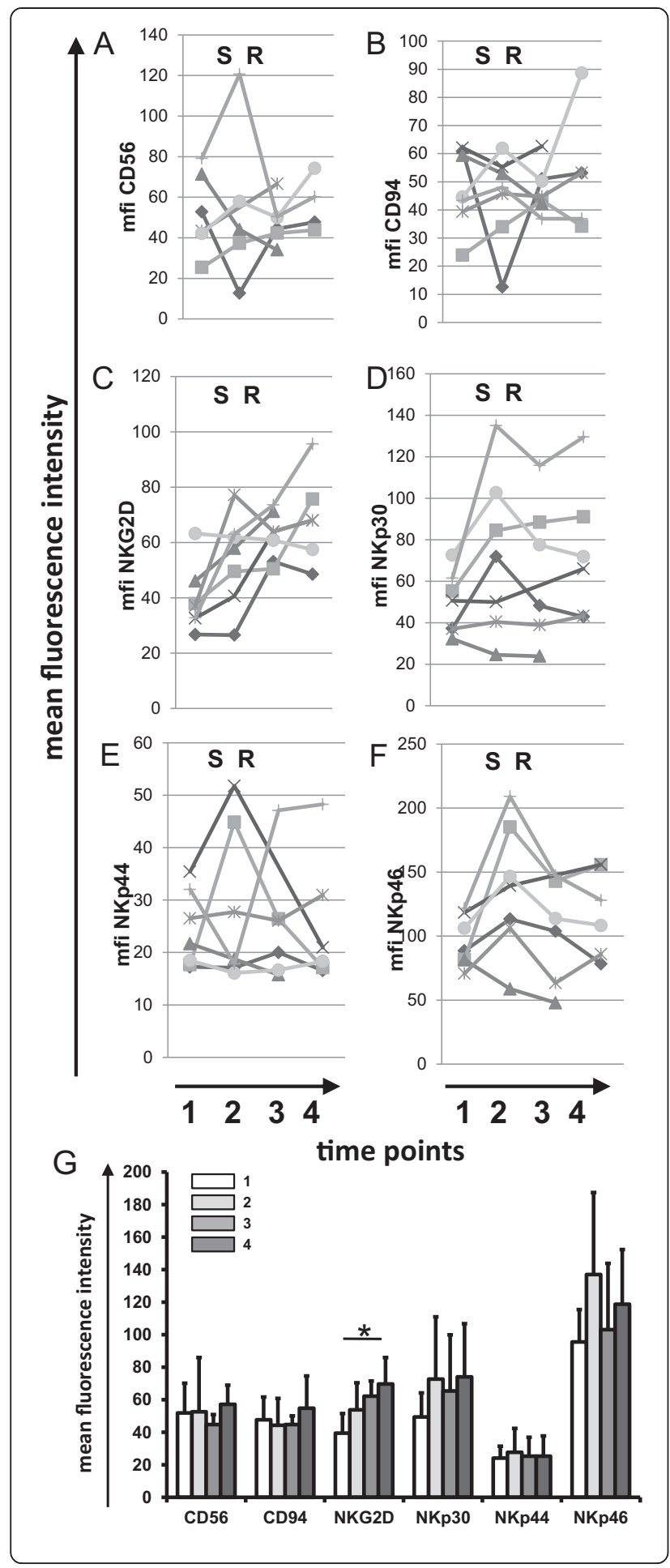

Figure 6 NK cell activatory markers on peripheral blood lymphocytes (PBL) of SCCHN patients before and at indicated time-points after therapy. EDTA blood samples from selected patients $(n=7)$ were collected at indicated time points before therapy (1), after tumor resection before start of radiation therapy (2), in the $1^{\text {st }}$ year of follow-up (3), and in the $2^{\text {nd }}$ year of follow-up (4). The time points of surgery and radiation are indicated with $S$ and $R$ in the upper part of each graph. NK cells were stained by using the lysis-wash method and analyzed by flow cytometry. A-F. CD56-positive and CD3-negative NK cells were gated and analyzed. Mean fluorescence intensity (mfi) of CD56, CD94, NKG2D, NKp30, NKp44, NKp46 were determined. Time-curves are shown for individual patients. G. Mean fluorescence intensity values of all markers of all patients with error bars and standard deviations $(n=7)$. Samples were taken before therapy (1), after tumor resection before start of radiation therapy (2), in the 1st year of follow-up (3), and in the 2 nd year of follow-up (4) * $p<0.05$.

studies with more patients will demonstrate whether diagnosis or clinical responses do correlate with sHsp70 levels [20].

The expression density of activatory NK cell markers which might be affected by the presence of sHsp70 protein in the serum was determined in peripheral blood lymphocytes of SCCHN patients before, during and after therapy. In recent studies we could show that especially the expression density of CD94 and NKG2D were found to be up-regulated upon stimulation with Hsp70 protein [21]. Herein, we could show that in all patients exhibiting sHsp70 the expression of NKG2D was significantly found to be up-regulated over time (Figure 6G). Future analysis will clarify whether the sHsp70 levels before therapy or changes of sHsp70 levels that are induced by therapy might be responsible for the increased expression of NKG2D on NK cells.

In summary, our data provide evidence that elevated sHsp70 protein levels in the blood of tumor patients are associated with the presence of primary malignant tumors in SCCHN patients. Furthermore, increased sHsp70 levels were found to be associated with increased tumor volumes. Since sHsp70 levels dropped in patients after removal of the tumor, we speculate that sHsp70 levels in the blood of patients might be useful not only for the detection of tumors but also for the monitoring of the therapeutic response to radiation therapy. Due to the finding that mHsp70 is associated with the capacity of tumor cells to actively release Hsp70 and due to the fact that mHsp70 positivity was determined on a broad variety of tumor entities such as colorectal, lung, pancreatic and prostate cancer [16,22-24], we assume that sHsp70 is also present in the serum of patients with other tumor entities. Future studies in larger cohorts and longer follow-up periods are necessary to determine the role of sHsp70 levels as a universal tumor biomarker. 


\section{Competing interests}

The authors declare that they have no competing interests.

\section{Authors' contributions}

MG performed experiments and drafted manuscript, HS collected blood samples and provided clinical data, CB performed ELISA experiments, MB collected tumor samples, BC collected tumor samples, MD collected blood samples, SB performed FACS analysis, KH performed ELISA, SL performed ELISA, VVP analyzed data, ES collected blood samples, TES analyzed data, MS performed collected blood samples, DS analyzed data, WS performed FACS analysis, SS performed FACS analysis, GM initiated the trial, analyzed data, drafted the Ms. All authors read and approved the final manuscript.

\section{Acknowledgements}

The authors thank Jessica Pelzel and Andrea Mair for excellent technical assistance and Henning Bier and Julia Hiller for providing tumor patient samples. This study was supported in parts by the DFG - Cluster of Excellence: Munich-Centre for Advanced Photonics, the German Federal Ministry of Education and Research (BMBF, 0313909), the m4 - Cluster of Excellence: Personalized Medicine (BMBF, 16EX1021C, 16GW0030), the SFB824/B4 (DFG), the BMBF Kompetenzverbund Strahlenforschung (03NUK007E), EU-CELLEUROPE (315963), Wilhelm Sander-Stiftung (2012.078.1) and by the Klinikum rechts der Isar, Technische Universität München (KKF:15-06). Eva Sage is supported by the phD program entitled "Translationale Medicine" which is provided by the Technische Universität München, Munich, Germany.

\section{Author details}

${ }^{1}$ Department of Radiation Oncology, Klinikum rechts der Isar, Technische Universität München, Munich, Germany. ${ }^{2} \mathrm{Hals}$-Nasen-Ohrenklinik und Poliklinik, Klinikum rechts der Isar, Technische Universität München, Munich, Germany. ${ }^{3}$ Clinical Cooperation Group - "Innate Immunity in Tumor Biology", Helmholtz Zentrum münchen, Munich, Germany.

Received: 6 January 2014 Accepted: 22 May 2014

Published: 9 June 2014

\section{References}

1. de Wit M, Fijneman RJ, Verheul HM, Meijer GA, Jimenez CR: Proteomics in colorectal cancer translational research: biomarker discovery for clinical applications. Clin Biochem 2013, 46:466-479.

2. Lin L, Piao J, Gao W, Piao Y, Jin G, Ma Y, Li J, Lin Z: DEK over expression as an independent biomarker for poor prognosis in colorectal cancer. BMC Cancer 2013, 13:366.

3. Abe M, Manola JB, Oh WK, Parslow DL, George DJ, Austin CL, Kantoff PW: Plasma levels of heat shock protein 70 in patients with prostate cancer: a potential biomarker for prostate cancer. Clin Prostate Cancer 2004, 3:49-53.

4. Fujita Y, Nakanishi T, Miyamoto Y, Hiramatsu M, Mabuchi H, Miyamoto A, Shimizu A, Takubo T, Tanigawa N: Proteomics-based identification of autoantibody against heat shock protein 70 as a diagnostic marker in esophageal squamous cell carcinoma. Cancer Lett 2008, 263:280-290.

5. Ciocca DR, Calderwood SK: Heat shock proteins in cancer: diagnostic, prognostic, predictive, and treatment implications. Cell Stress Chaperones 2005, 10:86-103.

6. Calini V, Urani C, Camatini M: Overexpression of HSP70 is induced by ionizing radiation in $\mathrm{C} 3 \mathrm{H} 10 \mathrm{~T} 1 / 2$ cells and protects from DNA damage. Toxicol In Vitro 2003, 17:561-566.

7. Rerole AL, Jego G, Garrido C: Hsp70: anti-apoptotic and tumorigenic protein. Methods Mol Biol 2011, 787:205-230.

8. Multhoff G: Heat shock protein 70 (Hsp70): membrane location, export and immunological relevance. Methods 2007, 43:229-237.

9. Lancaster GI, Febbraio MA: Exosome-dependent trafficking of HSP70: a novel secretory pathway for cellular stress proteins. J Biol Chem 2005, 280:23349-23355.

10. Asea A, Kraeft SK, Kurt-Jones EA, Stevenson MA, Chen LB, Finberg RW, Koo GC, Calderwood SK: HSP70 stimulates cytokine production through a CD14-dependant pathway, demonstrating its dual role as a chaperone and cytokine. Nat Med 2000, 6:435-442.

11. Gross C, Hansch D, Gastpar R, Multhoff G: Interaction of heat shock protein 70 peptide with NK cells involves the NK receptor CD94. Biol Chem 2003, 384:267-279.
12. Gastpar R, Gross C, Rossbacher L, Ellwart J, Riegger J, Multhoff G: The cell surface-localized heat shock protein 70 epitope TKD induces migration and cytolytic activity selectively in human NK cells. J Immunol 2004, 172:972-980.

13. Bayer C, Liebhardt ME, Schmid TE, Trajkovic-Arsic M, Hube K, Specht HM, Schilling D, Gehrmann M, Stangl S, Siveke JT, Wilkens JJ, Multhoff G: Validation of heat shock protein 70 as a tumor-specific biomarker for monitoring the outcome of radiation therapy in tumor mouse models. Int J Radiat Oncol Biol Phys 2014, 88:694-700.

14. Kleinjung T, Arndt O, Feldmann HJ, Bockmühl U, Gehrmann M, Zilch T, Pfister K, Schönberger J, Marienhagen J, Eilles C, Rossbacher L, Multhoff G: Heat shock protein 70 (Hsp70) membrane expression on head-and-neck cancer biopsy-a target for natural killer (NK) cells. Int J Radiat Oncol Biol Phys 2003, 57:820-826.

15. Krause SW, Gastpar R, Andreesen R, Gross C, Ullrich H, Thonigs G, Pfister K, Multhoff G: Treatment of colon and lung cancer patients with ex vivo heat shock protein 70-peptide-activated, autologous natural killer cells: a clinical phase I trial. Clin Cancer Res 2004, 10:3699-3707.

16. Dutta SK, Girotra M, Singla M, Dutta A, Otis Stephen F, Nair PP, Merchant NB: Serum HSP70: a novel biomarker for early detection of pancreatic cancer. Pancreas 2012, 41:530-534.

17. Dakappagari N, Neely L, Tangri S, Lundgren K, Hipolito L, Estrellado A, Burrows F, Zhang $H$ : An investigation into the potential use of serum Hsp70 as a novel tumor biomarker for Hsp90 inhibitors. Biomarkers 2010, 15:31-38.

18. Baumann M, Liertz C, Baisch H, Wiegel T, Lorenzen J, Arps H: Impact of overall treatment time of fractionated irradiation on local control of human FaDu squamous cell carcinoma in nude mice. Radiother Oncol 1994, 32:137-143.

19. Hurwitz MD, Kaur P, Nagaraja GM, Bausero MA, Manola J, Asea A: Radiation therapy induces circulating serum $\mathrm{Hsp} 72$ in patients with prostate cancer. Radiother Oncol 2010, 95:350-358.

20. De Maio A: Heat shock proteins: facts, thoughts, and dreams. Shock 1999, 11:1-12.

21. Gross C, Schmidt-Wolf IG, Nagaraj S, Gastpar R, Ellwart J, Kunz-Schughart LA, Multhoff G: Heat shock protein 70-reactivity is associated with increased cell surface density of CD94/CD56 on primary natural killer cells. Cell Stress Chaperones 2003, 8:348-360.

22. Mitchell PS, Parkin RK, Kroh EM, Fritz BR, Wyman SK, Pogosova-Agadjanyan EL, Peterson A, Noteboom J, O'Briant KC, Allen A, Lin DW, Urban N, Drescher CW, Knudsen BS, Stirewalt DL, Gentleman R, Vessella RL, Nelson PS, Martin $D B$, Tewari M: Circulating microRNAs as stable blood-based markers for cancer detection. Proc Natl Acad Sci U S A 2008, 105:10513-10518.

23. Kocsis J, Madaras B, Toth EK, Fust G, Prohaszka Z: Serum level of soluble 70-kD heat shock protein is associated with high mortality in patients with colorectal cancer without distant metastasis. Cell Stress Chaperones 2010, 15:143-151.

24. Zimmermann M, Nickl S, Lambers C, Hacker S, Mitterbauer A, Hoetzenecker K, Rozsas A, Ostoros G, Laszlo V, Hofbauer H, Renyi-Vamos F, Klepetko W, Dome B, Ankersmit HJ: Discrimination of clinical stages in non-small cell lung cancer patients by serum HSP27 and HSP70: a multi-institutional case-control study. Clin Chim Acta 2012, 413:1115-1120.

\section{doi:10.1186/1748-717X-9-131}

Cite this article as: Gehrmann et al:: Hsp70 - a biomarker for tumor detection and monitoring of outcome of radiation therapy in patients with squamous cell carcinoma of the head and neck. Radiation Oncology 2014 9:131. 